\title{
CATALUÑA, ENTRE LA AUTONOMÍA Y LA AUTODETERMINACIÓN (UNA PROPUESTA)
}

\author{
JOAN OLIVER ARAUJO \\ Catedrático de Derecho Constitucional \\ Universidad de las Islas Baleares
}

\section{SUMARIO}

I. Las reivindicaciones nacionalistas catalanas durante la Transición Política: causa y motivo de la descentralización de todo el Estado español. II. La crisis del actual Estado autonómico español: ¿es el federalismo la solución o, al menos, parte de la solución? III. La manifiesta insuficiencia del modelo federal clásico para Cataluña y el País Vasco: a la búsqueda urgente de una fórmula realista de convivencia estable dentro del Estado español. IV. Ya no se puede ni «conllevar»... la hora de la política en mayúsculas. V. La conveniencia (y, posiblemente, la necesidad) de que el pueblo de Cataluña (y, también, el del País Vasco) apruebe el nuevo encaje jurídico de su nación dentro del Estado español.

\section{LAS REIVINDICACIONES NACIONALISTAS CATALANAS DURANTE LA TRANSICIÓN POLÍTICA: CAUSA Y MOTIVO DE LA DESCENTRALIZACIÓN DE TODO EL ESTADO ESPAÑOL}

Durante el último proceso constituyente español, como reacción frente a la dictadura que se quería dejar atrás, la voluntad política de los principales partidos era clara: descentralizar el Estado español (aunque hubiera diferencias, muy marcadas, sobre el alcance que debía darse a dicha descentralización). Su finalidad política era obvia: dar satisfacción a las históricas pretensiones autonomistas catalanas y vascas, que - a través de un proceso de emulación y mimetismo- rápidamente se habían generalizado a todos los territorios del Estado, si bien con distinta intensidad. En efecto, a la muerte del general Franco «existían regiones con muy distinto grado de conciencia autonómica. Se sabía que muy acusada en Cataluña, País Vasco y, en menor medida, en Galicia. Y no se sabía casi nada o nada respecto de todas las demás. Pero a partir de la celebración de las elecciones 
de 15 de junio ya no sería así». En el otoño del año 1977, se produjo una «explosión de autonomismo» en la mayoría de los territorios del Estado español ${ }^{1}$.

Los deseos autonomistas — que se unieron de forma inseparable a la lucha por la libertad y la justicia (el coreado eslogan «libertad, amnistía y estatuto de autonomía» fue su expresión más popular) — aparecían como la lógica «respuesta, en forma de contrapunto, al Estado franquista anterior. La extrema centralización de este no hizo sino agudizar las viejas reivindicaciones» nacionalistas y regionalistas que, de forma cíclica, han marcado la historia política del Estado español ${ }^{2}$. Los regímenes preautonómicos, extendidos como un reguero de pólvora durante los años 1977 y 1978, ya indicaban de forma muy clara el posicionamiento político de los principales partidos y el camino que previsiblemente iba a recorrerse.

La Constitución, como es sabido, no dibujó un modelo territorial de Estado completo y cerrado, sino que estableció diversas vías para que, los territorios con derecho a ello, pudieran (si este era su deseo) acceder a los diversos grados de autonomía ${ }^{3}$. Pues bien, tras un proceso poco ejemplar ${ }^{4}$ que se prolongó desde 1979 a 1983, se dibujó de forma definitiva el mapa autonómico español: el anterior Estado unitario, en su totalidad, se descentralizó políticamente en diecisiete Comunidades Autónomas (cuatro de régimen especial —entre ellas, evidentemente, Cataluña-y trece de régimen ordinario). Puede afirmarse que el Estado autonómico ha sido el fruto, tal vez no suficientemente meditado ni previstas sus

1 Grupo de Reflexión creado por el PSOE-Andalucía sobre la reforma de la Constitución para el establecimiento de un modelo federal para España (en adelante, Grupo de Reflexión del PSOE-A): Por una reforma federal del Estado autonómico, Fundación Alfonso Perales, Sevilla, 2012, apartado 1, p. 20. Este Grupo de Reflexión estuvo integrado por los siguientes miembros: G. Cámara Villar (coordinador del Grupo y de los trabajos de la Comisión 1, que ha elaborado el apartado 1), M. Azpitarte Sánchez (ha coordinado los trabajos de la Comisión 4, que ha elaborado el apartado 4), M.L. Balaguer Callejón, C. Calvo Poyato, M. Carrasco Durán, M. Chaves González, E. Gómez Corona, M. Medina Guerrero (ha coordinado los trabajos de la Comisión 6, que ha elaborado el apartado 6), J.A. Montilla Martos (ha coordinado los trabajos de la Comisión 5, que ha elaborado el apartado 5), B. Oliver León, B. Rodríguez Ruiz (ha coordinado los trabajos de la Comisión 3, que ha elaborado el apartado 3), F. Pérez Royo, J. Pérez Royo (ha coordinado los trabajos de la Comisión 2, que ha elaborado el apartado 2), J. A. Pérez Tapias y J. Sánchez Maldonado.

2 De Esteban Alonso, J.: «Parte introductoria», en el libro colectivo El régimen constitucional español (directores: J. De Esteban Alonso y L. López Guerra), Labor Universitaria, Barcelona, 1980, vol. I, p. 57.

3 Como afirma el profesor C. Viver i PI-Sunyer (Las autonomías políticas, Instituto de Estudios Económicos, Madrid, 1994, pp. 9-11), la Constitución «no crea las Comunidades Autónomas, ni determina cuáles deben constituirse, ni fija, positiva o negativamente, sus competencias. En sus artículos 143.1 y 144 se limita a precisar los sujetos que pueden — si quieren — ejercer el derecho a la autonomía y deja libertad para que los Estatutos atribuyan a las respectivas Comunidades Autónomas las competencias que crean convenientes, con dos limitaciones (...). Así pues, la Constitución dejaba abierta la posibilidad de generalizar o no el sistema autonómico a todo el territorio estatal y, en consecuencia, dejaba abiertas las cuestiones relativas al número y magnitud de las Comunidades Autónomas y a la igualación o no de los niveles competenciales de las mismas».

4 Tomás Villarroya, J.: «Proceso autonómico y observancia de la Constitución», en Revista Española de Derecho Constitucional, n. ${ }^{\circ}$ 15, 1985, pp. 25-64; Ruiz Miguel, C.: «Los vicios de origen de los procesos autonómicos», en Teoría y Realidad Constitucional, n. ${ }^{\circ} 24,2009$, pp. 243-264. 
consecuencias políticas, «de la ausencia de una voluntad constituyente... respecto de la estructura del Estado» ${ }^{5}$.

De este modo, a principios de 1983 se culminó el proceso constitutivo de las diecisiete Comunidades Autónomas que, a partir de entonces, iban a estructurar territorialmente el Estado español. El profesor Eliseo Aja — ya en 1999- afirmó, de forma certera, que España, en poquísimas décadas, había pasado de ser «el Estado más centralista de Europa» a ser «uno de los más descentralizados», comparable en este aspecto a Estados federales clásicos como Alemania, Austria o Suiza $^{6}$. La descentralización española fue, desde esta óptica, un éxito de dimensiones históricas, que nadie seriamente discute ${ }^{7}$. De hecho, el Estado anterior a la Constitución de 1978 se entendía por sí solo; en cambio, el Estado de 2016 solo «se entiende en relación con las Comunidades Autónomas» ${ }^{8}$.

No estará de más recodar, en este punto de nuestro razonamiento, que fue precisamente la presión de catalanes y vascos la que determinó que la Constitución de 1978 abriera, de par en par, las puertas a la descentralización política de todo el Estado español. Dicho de forma más clara: las Comunidades Autónomas ordinarias existen porque Cataluña y el País Vasco, que fueron decisivas en el tránsito de la dictadura a la democracia y en la elaboración de la Constitución, tuvieron suficiente fuerza política, pedigrí democrático y habilidad negociadora para que la satisfacción de sus reivindicaciones de autonomía apareciera, a los ojos de la clase política española de entonces, como requisito indispensable para la construcción en España de un Estado democrático viable. Sobre esta circunstancia, el profesor Torres del $\mathrm{Moral}^{9}$ ha escrito lo siguiente: los partidos políticos nacionalistas «esgrimían como bagaje democrático su presencia en la II República y su antifranquismo durante la Dictadura, y lograron que la opinión dominante en la clase política española de la Transición aceptara que la legitimidad democrática del sistema político que estaba construyéndose pasaba ineludiblemente por la presencia en él de dichas fuerzas políticas». En el mismo sentido, el profesor Astrid Barrio y otros autores ${ }^{10}$ han afirmado que la fuerza de los partidos de ámbito no estatal, «en especial en Cataluña y el País Vasco, acabó por hacer indisociable la lucha por la democracia de las reivindicaciones nacionales durante la Transición. El peso electoral y parlamenta-

5 Grupo de Reflexión del PSOE-A: Por una reforma..., op. cit., apartado 1, p. 19.

6 Aja Fernández, E.: El Estado autonómico. Federalismo y hechos diferenciales, Alianza Editorial, Madrid, 1999 , p. 14

7 SÁnchez Morón, M.: «Reformar el Estado; ¿modificar la Constitución? Apuntes para el debate», en El Cronista del Estado Social y Democrático de Derecho, n. ${ }^{\circ} 34,2013$, p. 34

8 Grupo de Reflexión del PSOE-A: Por una reforma..., op. cit., apartado 1, p. 20.

9 Torres del Moral, A.: «La reforma del sistema electoral o la cuadratura del círculo», en Revista de Derecho Político, n. ${ }^{\circ} 74,2009$, p. 60.

10 Barrio López, A.; Rodríguez Teruel, J.; Baras Gómez, M.; y Barberà Aresté, Ò.: Partidos de ámbito no estatal y gobernabilidad multinivel: el caso de España (1977-2008), Institut de Ciències Polítiques i Socials, Barcelona, 2010 («Working Papers» n. ${ }^{\circ}$ 291), p. 3. 
rio alcanzado por nacionalistas vascos y catalanes en las primeras elecciones democráticas tuvo su reflejo en el título VIII de la Constitución Española, que dio lugar al desarrollo del Estado autonómico».

\section{LA CRISIS DEL ACTUAL ESTADO AUTONÓMICO ESPAÑOL: ¿ES EL FEDERALISMO LA SOLUCIÓN O, AL MENOS, PARTE DE LA SOLUCIÓN?}

\section{El Estado autonómico no da más de sí}

Sin desconocer ni negar el éxito del proceso descentralizador al que acabamos de referirnos, hay que reconocer que nuestro Estado autonómico presenta, tras más de treinta años de funcionamiento, notables insuficiencias, evidentes defectos, peligrosas ambigüedades y grandes disfunciones. Además, lo cual tal vez sea lo más grave de todo, una parte cada vez mayor de la sociedad española lo ve como un grave problema y no como la solución razonable a la compleja convivencia entre los diversos pueblos que integran el Estado español. Ciertamente, para el ciudadano de a pie lo importante es liberar a España «de tanto abuso, de políticos afincados por doquier lucrándose del erario público. Para los juristas la cuestión es bastante más seria. Constatamos el despilfarro y la desmesura organizativa, desde luego, pero también que el título octavo de la Constitución, concerniente a la organización del Estado, ha dejado de aplicarse, que existe una convivencia caótica de normas estatales y autonómicas» inmanejable ${ }^{11}$ y que las relaciones entre el Estado central y las autonomías parecen inspirarse en la desconfianza y la deslealtad, cuando no en la manifiesta enemistad. Además, como ha afirmado el profesor Ferran Requejo ${ }^{12}$, por lo que se refiere a la cuestión territorial, la Constitución de 1978 «pagó el precio de las indefiniciones y ambigüedades. Recordamos que se hizo con un ejército amenazante, aún muy vinculado a la dictadura, y bajo la dirección de élites surgidas del régimen anterior. Quedaron sin definir aspectos fundamentales susceptibles de interpretaciones no solo diferentes, sino contradictorias. Se creía que el esfuerzo de consenso que posibilitó aprobar el Texto Constitucional permitiría resolver los conflictos de futuro. Error. Más de tres décadas después, el modelo autonómico se ha vuelto obsoleto en términos de reconocimiento y acomodación del pluralismo, y de autogobierno efectivo (interpretación de derechos, leyes de bases, leyes orgánicas, competencias de ejecución, política europea, etcétera)».

11 Muñoz Machado, S.: Informe sobre España. Repensar el Estado o destruirlo, Crítica, Barcelona, 2012, p. 19 (el primer capítulo de este excelente libro, tan sugerente como provocador, se publicó en El Cronista del Estado Social y Democrático de Derecho, n. ${ }^{\circ} 32,2012$, pp. 4-8).

12 Requejo Coll, F. «Democracia, pluralismo, bienestar», en La Vanguardia, día 1 de marzo de 2013 , p. 26. 
España — como ha indicado el profesor García Roca ${ }^{13}$ — «es un Estado compuesto que fue diseñado con ingredientes regionales que, en su mayor parte, derivan de la Constitución Española de 1931 y de la Constitución Italiana de 1947 a su vez influida por aquella. En especial, el discutible principio dispositivo o de voluntariedad — se describió como la "autonomía a la carta"— que fue pensado en la II República para un regionalismo como excepción: solventar el llamado «problema catalán», puesto que el autogobierno era ya un hecho en las calles, pero sin querer generalizar la autonomía a otras regiones que no lo deseaban. Una idea extraña a la actual generalización en diecisiete Comunidades Autónomas y dos ciudades autónomas donde la inspiración de ese principio solo encaja con calzador y serias dificultades. De ahí — concluye el catedrático de la Universidad Complutense - emanan muchas de las asimetrías normativas y disfuncionalidades competenciales tras sucesivas y constantes reformas» de los Estatutos de Autonomía. Más crítico se muestra aún el profesor Sánchez Morón ${ }^{14}$, al afirmar que «el modelo autonómico es claramente imperfecto en lo que se refiere a las reglas de reparto de las competencias, insuficiente en lo que atañe a las fórmulas de coordinación y cooperación intergubernativa, discutible y siempre polémico en el aspecto de la financiación de las Comunidades Autónomas y prolífico en la creación de órganos, entidades y estructuras políticas y administrativas de todo tipo, de manera que sus deficiencias han acabado por tener un alto coste para los ciudadanos».

Reflexionando sobre la enorme dispersión normativa sobrevenida, el profesor García Ruiz ${ }^{15}$ subraya que esta «resulta suicida», afirmando de forma gráfica que «hasta los toreros necesitan asesoramiento, según donde lidien, para saber qué reglamento se les aplica y que ha conducido a unas fragmentaciones del mercado cuyos costes ya no nos podemos permitir ¿Qué hemos hecho — se preguntabapara que una sola de nuestras Comunidades Autónomas promulgue en un año más normas que toda Alemania, es decir incluyendo sus dieciséis Lander?».

\section{La necesidad de federalizar el Estado español: un proceso racionalizador}

Aunque desde una perspectiva material, esto es, atendiendo únicamente al grado de competencias asumido por los entes territoriales, nuestro Estado autonómico puede equiparse a un Estado federal, hay que afirmar rotundamente que el Estado autonómico español no es un Estado federal. Ello se debe no solo a cuestiones de ingeniería constitucional (como, por ejemplo, el papel que juega el Senado,

13 García Roca, J.: «¿Reforma constitucional en clave federal?», en El Cronista del Estado Social y Democrático de Derecho, n. ${ }^{\circ} 34,2013$, p. 22.

14 SÁnChez Morón, M. «Reformar...», op. cit., p. 33.

15 García Ruiz, J.L.: «Trayectoria y perspectiva del Estado autonómico», en El Cronista del Estado Social y Democrático de Derecho, n. ${ }^{\circ} 31,2012$, p. 58.

UNED. Teoría y Realidad Constitucional, núm. 37, 2016, pp. 221-248 
la composición del Tribunal Constitucional o la estatalidad de los entes territoriales federados), sino prioritariamente a «un problema de legitimidad. El Estado autonómico carece de legitimidad federal (es decir, de foedus, de pacto). No es el resultado de un pacto constitucional en el que se defina la posición del Estado y de cada una de las nacionalidades y regiones que se integran en el mismo, sino que es el resultado de una de las posibles interpretaciones» de la Constitución de 1978. Desde dicha perspectiva, «el Estado federal no puede ser solo punto de llegada, sino que tiene que ser punto de partida. Exige un pacto federal, un consentimiento expreso de cada nacionalidad o región a su posición en el Estado» ${ }^{16}$.

A nuestro juicio, se hace necesario, desoyendo interesados cantos de sirena que proponen la vuelta a un modelo más o menos centralista, dar un paso más en aquel proceso descentralizador, un paso que, por decirlo de algún modo, sería el normal desarrollo de los principios que ya preñaban la Carta Magna de 1978: la constitucionalización y, posterior, implementación de un Estado federal, con todas sus consecuencias organizativas, competenciales, financieras y de coordinación y colaboración entre la Federación y los Estados-miembros y entre los Estados-miembros entre sí. Se trata, dicho sin rodeos, de reformar el Estado autonómico español siguiendo el modelo federal alemán. Lo que exigirá un trabajo de adaptación y modificación de las técnicas constitucionales y otro dirigido al logro de la legitimidad federal del nuevo Estado descentralizado. Con criterio análogo, el profesor García Roca ${ }^{17}$ ha subrayado que el Estado autonómico español «debería evolucionar en clave federal, entre otras razones, porque desaparecido el Estado regional en Bélgica y ampliamente cuestionado en Italia no tenemos otros referentes comparados que los federales que puedan auxiliarnos a solventar concretos problemas». Por ello, continúa afirmando, «deberíamos reforzar con prudencia y realismo nuestra dimensión federal, pues es su evolución natural como ha ocurrido ya en otros países inicialmente regionales».

Como escribía hace más de una década el profesor Blanco Valdés ${ }^{18}$, es preciso adoptar las medidas jurídico-políticas destinadas a completar lo que falta aún para que nuestro Estado descentralizado pueda funcionar correctamente como un Estado federal. Y, como apuntaba el catedrático de la Universidad de Santiago de Compostela, entre dichas medidas hay que incluir «la mejora de la cooperación entre las Comunidades (y entre estas y el Estado) a través de las denominadas conferencias sectoriales; la consolidación de la (...) Conferencia de Presidentes Autonómicos ${ }^{19}$; el rodaje y perfeccionamiento de los mecanismos $(\ldots)$ para la

16 Grupo de Reflexión del PSOE-A: Por una reforma..., op. cit., apartado 1, p. 18 (la cursiva es nuestra).

17 García RocA, J.: « ¿Reforma...», op. cit., pp. 22-23 (la cursiva es nuestra).

18 Blanco Valdés, R.: «Constitución, descentralización, federalismo: ¿Qué se puede aprender de la experiencia española?», en el libro colectivo El Estado autonómico in fieri. La reforma de los Estatutos de Autonomía (coordinador: M.J. Terol Becerra), Instituto Andaluz de Administración Pública, Sevilla, 2005, pp. 60-61.

19 Sobre este interesante cauce para la cooperación en el Estado autonómico, puede verse el trabajo de L.A. GÁlvez Muñoz y J.G. Ruiz GonzÁlez titulado: «Estado autonómico, cooperación intergubernamental y Conferencia de Presidentes», en Revista de Derecho Político, n. ${ }^{\circ}$ 86, 2013, pp. 229-253. 
participación de las Comunidades Autónomas en las instancias europeas; o, las mucho más complejas, de la reforma del Senado o de la fijación de un mapa competencial razonablemente estable». Estas medidas, en lo posible, deberían reducir uno de los defectos más enquistados del actual «sistema (el de la bilateralidad Estado central/autonomías) y eliminar alguno de sus problemas asociados: desde el mercadeo de competencias hasta (...) esa incertidumbre, casi endémica, respecto de la futura evolución del modelo autonómico español». Es necesario reducir al máximo de lo razonable la bilateralidad ${ }^{20}$, apostando decididamente por la multilateralidad. Es imprescindible para lograr estos objetivos superar el voluntarismo y el nominalismo, creando y reforzando, cuando sea preciso, los mecanismo e instrumentos idóneos para ello. El federalismo, como nos muestra claramente el Derecho comparado, «proporciona modelos muy flexibles de gobierno plural y multinivel, fundamentados en el consentimiento mutuo, en el coejercicio del poder político y en la colaboración y cooperación, con gran capacidad para conciliar los diferentes sentimientos identitarios de pertenencia, sin exclusiones, mediante una estructura política de integración en una realidad global que se sobrepone e integra a las partes que la componen» y donde el principio de subsidiariedad será la clave para la distribución del poder ${ }^{21}$.

\section{LA MANIFIESTA INSUFICIENCIA DEL MODELO FEDERAL CLÁSICO PARA CATALUÑA Y EL PAÍS VASCO: A LA BÚSQUEDA URGENTE DE UNA FÓRMULA REALISTA DE CONVIVENCIA ESTABLE DENTRO DEL ESTADO ESPAÑOL}

1. La realidad es tozuda: catalanes y vascos, a diferencia del resto de ciudadanos del Estado, quieren un grado de autogobierno (siempre) mayor

La tesis que hemos defendido en el epígrafe anterior y que consideramos acertada, esto es, que el Estado autonómico español debe transformarse en un Estado federal siguiendo el modelo alemán, quedaría, sin embargo, muy incompleta si no pusiéramos sobre la mesa el hecho de que los nacionalistas catalanes y vascos, desde hace ya algunas décadas, se oponen radicalmente al Estado federal. Esta oposición tiene su raíz, aunque habitualmente no lo expresen con tanta claridad, en el hecho de que este modelo de Estado implicaría per se la igualdad —al menos competencial y posiblemente bastante más- de todos los entes territoria-

20 «La bilateralidad ha sido el principio del Estado Autonómico (...). Cada nacionalidad o región ha tenido relación exclusivamente con el Estado en el momento de constituirse en Comunidad Autónoma. Y cada Comunidad Autónoma ha seguido manteniendo relación casi exclusivamente con el Estado una vez constituida». Vid. Grupo de Reflexión del PSOE-A: Por una reforma..., op. cit., apartado 1, p. 18.

21 Grupo de Reflexión del PSOE-A: Por una reforma..., op. cit., apartado 1, p. 29. 
les federados (de nuevo el «café para todos», aunque ahora fuera un café con cafeína). Circunstancia que repugna al pensamiento nacionalista, que quiere ver su singularidad política (esto es, su deseo tendencialmente independentista) reconocida tanto en las normas de la Federación (empezando por la propia Constitución) como en la realidad, interna e internacional.

Cataluña y el País Vasco, se quiera o no se quiera, guste o no guste, son Comunidades Autónomas (ahora el nombre es lo de menos) distintas a las otras quince. El profesor Jorge de Esteban ${ }^{22}$, nada sospechoso de simpatías con los nacionalismos periféricos, afirma, con honestidad intelectual, que hay que ser «conscientes de que Cataluña, como el País Vasco, no es una mera región española, sino algo más, lo que se debe tener siempre en cuenta». Ambos territorios son —añadimos nosotros - verdaderas naciones, tanto si aceptamos la definición estática como la definición dinámica del concepto de nación. En efecto, desde una perspectiva estática, se ha considerado la nación como algo hecho para siempre, como algo natural, que se puede definir por una serie de características comunes (entre otras, la lengua, las costumbres, la historia, la religión, el derecho propio, los mitos populares, los héroes colectivos, etc.). Pues bien, a nuestro entender, tanto catalanes como vascos cumplen, en un grado muy significativo, estos rasgos diferenciadores. Pero todavía más importante que la concepción estática de nación es, a nuestro juicio, la perspectiva dinámica. Los que comparten esta visión afirman que la nación no es algo hecho de una vez para siempre, sino algo que se va construyendo día a día. Dentro de esta concepción, destaca el pensamiento de Ernest Renan, que — en una conferencia, dictada en la Sorbona de París el 11 de marzo de 1882, titulada: «QQué es una nación?»— afirmó que la nación es un «plebiscito cotidiano». No muy lejos de este planteamiento se encuentra José Ortega y Gasset en su obra España invertebrada (1921), cuando afirma que la nación deriva de la voluntad y el sentimiento de tener que realizar una tarea en común ${ }^{23}$. En síntesis, de acuerdo con esta interpretación, lo decisivo para definir una nación no es el pasado, sino el futuro que colectivamente se desea, esto es, el devenir que se quiere compartir. Pues bien, es evidente, a nuestro parecer, que muchísimos catalanes y vascos desean ser, utilizando una expresión políticamente incorrecta, «una unidad de destino en lo universal». Es decir, ambicionan que su nación posea estructuras políticas propias de Estado, esto es, que logre separarse de España (a ser posible por vías amistosas y consensuadas) y adquiera estatus de Estado independiente dentro de la comunidad internacional, con asiento en la Asamblea General de las Naciones Unidas y reconocimiento generalizado por los otros Estados. Subrayan, en defensa de su opción independentista, que la historia,

22 De Esteban Alonso, J.: «La escalada de Cataluña hacia la independencia», en El Cronista del Estado Social y Democrático de Derecho, n. ${ }^{\circ} 39,2013$, p. 11.

23 López Guerra, L.: Apuntes de Derecho Político I, Universidad de Extremadura, Cáceres, 1979, vol. I, pp. 80-81; Oliver Araujo, J.: Política y Derecho, Tirant lo Blanch-Universitat de les Illes Balears, Valencia, 1996, pp. 107-109; Idem: La Constitución día a día, Tirant lo Blanch, Valencia, 2003, pp. 29-31. 
antigua y moderna, es un catálogo amplísimo de Estados que han nacido, que se han extinguido o que se han transformado (Europa en los último cien años ofrece, en este sentido, numerosos y constantes ejemplos). El hombre y su deseo de felicidad son permanentes..., los Estados son estructuras jurídico-políticas históricas, más o menos, efímeras.

No sabemos con certeza, pues el Gobierno español no permite realizar un referéndum con todas las garantías para saberlo, si estos catalanes y vascos que quieren la independencia de sus territorios son mayoría o no, pero lo cierto es que los separatistas de ambos territorios van incrementando el número de sus apoyos elección tras elección. Si en los comicios autonómicos de la primera década del siglo Xxi, los catalanes partidarios de la independencia no superaban el veinte por ciento de los sufragios (los que obtenía Esquerra Republicana de Catalunya), las últimas elecciones al Parlamento catalán (27 de septiembre de 2015) les dan un resultado que roza el cincuenta por ciento de los votantes. En efecto, con una participación altísima (de casi el 78\% del censo), los resultados muestran que la ciudadanía catalana está dividida en dos mitades, casi al cincuenta por ciento. En efecto, el $48 \%$ de los electores han dado su voto a opciones indudablemente independentistas - Junts pel Sí y la CUP-), en tanto que el 52\% lo ha dado a opciones españolistas o, para ser más exactos, a formaciones política no independentistas. Además, siendo honestos, hay que reconocer que no todos los votantes de la coalición «Catalunya Sí que es Pot» (que obtuvo el 8'9 de los sufragios) ${ }^{24}$ pueden considerarse contrarios a la independencia, pues algunos de sus dirigentes más destacados expresaron su apoyo a la secesión, aunque en estas elecciones daban prioridad al factor socio-económico sobre el elemento identitario. En fin - punto arriba, punto abajo_-, la mitad de los catalanes quiere irse de España y la otra mitad quiere quedarse (aunque en este segundo bloque, las diferencias sobre cómo quedarse son muy notables). Como afirma Jordi Matas Dalmases $^{25}$, a pesar de la política del miedo practicada sistemáticamente desde el Estado, «el soberanismo catalán no está descendiendo, sino que se está transformando, y prefiere apoyar a formaciones políticas que defienden con mayor claridad y rotundidad la independencia de Cataluña». De hecho, con los datos demoscópicos en la mano, Robert Liñeira ${ }^{26}$ ha demostrado que las dos tendencias más evidentes en la Cataluña de los últimos años son «el incremento del apoyo a la independencia y la caída de los partidarios del mantener el actual encaje de Cataluña dentro de España».

24 La coalición de izquierdas «Catalunya Sí que es Pot», liderada por L. Rabell, era una alianza entre Iniciativa per Catalunya Verds, Esquerra Unida i Alternativa, Podemos y Equo.

25 Matas Dalmases, J.: «Independentismo "hard"», en El País (edición de Cataluña), día 23 de marzo de 2015, p. 2

26 LiÑ̃ira SÁNCHez, R.: Cataluña ante la consulta sobre la independencia. Participación, voto y motivaciones, Institut de Ciències Polítiques i Socials (adscrito a la Universidad Autónoma de Barcelona), Barcelona, 2013 (colección Quaderns de l'ICPS, n. ${ }^{\circ}$ ), p. 4.

UNED. Teoría y Realidad Constitucional, núm. 37, 2016, pp. 221-248 
Quien no quiera cerrar intencionadamente los ojos a la realidad, constatará que tanto en Cataluña como en el País Vasco las opciones independentistas van incrementando progresivamente el número de sus partidarios. Con ello, no queremos expresar ninguna valoración - positiva o negativa - sobre esta circunstancia, simplemente deseamos dejar constancia de una realidad que se muestra muy firme a lo largo del tiempo. Ignorarla, minimizarla, criticarla o ridiculizarla (como se hace, a menudo, desde medios de comunicación que son, legítimamente, muy españolistas) no va a cambiar un ápice la situación, al menos en el sentido que ellos desearían. Como afirma Mateu Morro, «la realidad no existe como nosotros querríamos que fuese por el simple hecho de nombrarla. La realidad es la que es, sólida, persistente (a veces, pétrea) y al margen de nuestra capacidad nominativa».

Pues bien, lo que a nosotros ahora nos interesa destacar es que la principal diferencia de Cataluña con Extremadura y del País Vasco con Murcia no son los rasgos externos (definidores del concepto estático de nación), que evidentemente existen y no son despreciables, sino su voluntad de pertenencia política (definidora del concepto dinámico de nación), que en las dos primeras Comunidades se concreta en un voto amplísimo (casi mayoritario) a partidos independentistas y, por el contrario, en las dos segundas, a partidos netamente españolistas. Y esto es lo esencial, a nuestro juicio, para considerar que Cataluña y el País Vasco son, por encima de lo que declaren las Cortes Generales o de lo que decida el Tribunal Constitucional, verdaderas naciones, no remedos de las mismas en forma de nacionalidades o regiones. Repito que no pretendemos hacer una valoración, sino simplemente una descripción, eso sí,... sin miopías intencionadas.

2. Una solución razonable (el «federalismo asimétrico» 0 «federalismo dual»): el reconocimiento constitucional de un estatus jurídico específico a Cataluña y al País Vasco a modo de Estados-libres-asociados, que les otorgue el máximo autogobierno compatible con el Estado español

La organización básica y las competencias de los quince Estados-miembros de la Federación Española deben ser iguales para todos ellos y venir establecidas por la propia Constitución. Sin embargo, es imprescindible — si queremos que, a medio plazo, el Estado español siga manteniendo sus actuales límites territoriales, sin tensiones insoportables- que reconozca un régimen político especial (de organización, competencias, financiación, lengua y relaciones exteriores) a Cataluña y al País Vasco. De este modo, el Estado Federal español estaría integrado, por una parte, por quince «Estados-miembros» 0 «Estados-federados de régimen común»y, por otra, por dos «Estados-libres-asociados», que gozarían, en todos los ámbitos, del máximo nivel de autogobierno compatible, jurídica y políticamente, con la exis- 
tencia del Estado español en sus actuales fronteras ${ }^{27}$. Este diferente estatus jurídico, como ya hemos intentado explicar, no tendría su principal fundamento en la existencia de rasgos diferenciales más o menos pronunciados, ni mucho menos en la existencia de ciudadanos de primera y de segunda categoría, sino en la reiterada voluntad de una parte muy importante de los pueblos catalán y vasco (tal vez, ya mayoritaria) de ser quienes $\operatorname{son}^{28}$ hasta sus últimas consecuencias, no solo ante la Federación Española y los Estados-miembros que la integrarían, sino también ante la comunidad internacional.

La realidad, como decíamos, es persistente y - a pesar de los deseos- negarla no la cambia. Es preciso legislar para la realidad que existe, no para la que quisiéramos que existiera. $\mathrm{Y}$, a nuestro juicio, con esta fórmula territorial, es posible que la mayoría de catalanes y vascos pudieran, al menos a día de hoy (aunque el tiempo corre en contra), ver satisfechas sus altísimas pretensiones de autogobierno y reconocidas sus específicas diferencias que les permiten definirse, sin ninguna duda, como naciones en pie de igualdad con las más antiguas del mundo ${ }^{29}$. Con ello, se cambiaría profundísimamente el statu quo político de Cataluña y del País Vasco, que es una petición mayoritaria y transversal de ambos pueblos, sin necesidad de levantar muros ni fronteras.

No se nos escapa que este modelo federal «asimétrico»o «dual» no está exento de serios problemas políticos y técnicos. Los primeros derivados del hecho de que, aunque la mayoría de catalanes y vascos posiblemente respaldarían esta nueva forma de organización política, numerosos ciudadanos del resto del Estado español, tal vez, la vería con desconfianza y animadversión, cuando no con declarada hostilidad. Por lo que se refiere a las dificultades técnicas, derivan del necesario encaje de un puzle ciertamente complejo, aunque tenemos en el Derecho extranjero ejemplos que, en cierta medida, nos pueden ilustrar (el Estado de Massachusetts, el Estado Libre de Baviera, el Estado Libre Asociado de Puerto Rico, el land alemán de Baden-Wütemberg, la República y Cantón de Ginebra, etc.). De hecho, como rezaba la divisa de Ernesto de Bradenburgo, «ad augusta per angusta», es decir, que solo se logran grandes objetivos (en este caso, la resolución definitiva de la «cuestión territorial» catalana y vasca) venciendo grandes dificultades.

Intentando ser imaginativos, lo que no siempre y necesariamente es un defecto, apuntamos, con la necesaria brevedad y concisión, algunas de las notas que deberían adornar - a nuestro juicio, obvio es decirlo- el régimen jurídico constitucional de los dos Estados-libres-asociados (Cataluña y el País Vasco):

27 Oliver Araujo, Joan: «España en la encrucijada», en la obra colectiva El futuro territorial del Estado español ¿Centralización, autonomía, federalismo, confederación o secesión? (director: Joan Oliver Araujo), Tirant lo Blanch, Valencia, 2014, pp. 33-96, esp. pp. 68-83.

28 Ya el maestro ViCENS VIVES — en su obra clásica Nosaltres, els catalans (primera edición de 1954) afirmaba que el primer rasgo que define a los catalanes es lo que él llamaba «la voluntad de ser».

29 Gutiérrez-Rubí, A.: «Votar, decidir, opinar», en El País (edición de Cataluña), día 23 de marzo de 2015 , p. 4.

UNED. Teoría y Realidad Constitucional, núm. 37, 2016, pp. 221-248 
1. Primera singularidad. Cataluña y el País Vasco deberían tener atribuidas todas las competencias que no son estrictamente necesarias al Estado español para poder entender que su territorio se extiende también sobre los dos Estados-libres-asociados. Todo lo demás debería ser competencia estatal (y no federal). Este sería el principio fundamental sobre el que gravitaría la relación del nuevo Estado compuesto español con Cataluña y el País Vasco. De dicho principio, como es obvio, se derivan un amplio conjunto de consecuencias de profundo calado, que afectan prácticamente a todos los ámbitos del derecho y de la política. Sin embargo, somos conscientes que estamos acudiendo, en estos momentos, a un complejo concepto jurídico indeterminado para hacer el reparto competencial o, dicho con otras palabras, para determinar a qué alcanza este mínimo que debe reservarse la Federación para poder mantener, de forma razonable, que las cuatro provincias catalanas y las tres vascas forman parte (aunque sea sui generis) del Estado español. A nuestro juicio, una parte de las materias (y submaterias o sectores de estas materias) que el artículo 149.1 CE atribuye actualmente al Estado de forma exclusiva deberían pasar a ser competencia de los dos Estados-libres-asociados. Además, los conflictos que pudieran producirse en este reparto — que, como en todo Estado compuesto, serían inevitables, aunque no superiores a los que se dan en nuestro Estado autonómico- serían resueltos por un nuevo Tribunal Conflictual (distinto del actual Tribunal Constitucional, que seguiría ejerciendo este cometido en relación con los quince Estados-miembros), integrado por ocho magistrados, cuatro propuestos por el Estado, dos propuestos por Cataluña y dos propuestos por el País Vasco.

2. Segunda singularidad. Cataluña y el País Vasco deberían contar con un sistema fiscal basado directamente en el actual concierto vasco ${ }^{30}$. De hecho, los pro-

30 Los rasgos fundamentales del concierto vasco se pueden sintetizar en los siguientes seis puntos. Primero: la Comunidad Autónoma «ingresa en su hacienda el rendimiento de prácticamente todos los tributos producidos o soportados en su territorio». Segundo: la Comunidad Autónoma «tiene capacidad normativa para diseñar los elementos fundamentales de los impuestos directos y, parcialmente, de algunos de los indirectos» (respetando algunos principios y reglas). Tercero: la Comunidad Autónoma «tiene atribuida la gestión sobre la casi totalidad de los tributos. Concretamente, le corresponde su liquidación, recaudación, inspección, revisión administrativa de las reclamaciones y ejercicio de la potestad sancionadora». Cuarto: la Comunidad Autónoma «devuelve al Estado una parte de los ingresos tributarios obtenidos y lo hace, aplicando como criterio para determinar la cuantía de la cuota de retorno, no el de la necesidad de gasto de la Comunidad para financiar el ejercicio de sus competencias, sino el criterio de la contribución a todas las cargas del Estado que no asuma la Comunidad Autónoma, más las que deriven del principio de solidaridad en los términos previstos en la Constitución y el Estatuto de Autonomía». Quinto: la existencia del modelo financiero del concierto vasco «está garantizado jurídicamente ante los cambios unilaterales impuestos por el Estado como consecuencia de ser el fruto de un pacto bilateral entre el Estado y la Comunidad Autónoma: es necesaria la concurrencia de la voluntad del Estado y de la Comunidad Autónoma para establecerlo, para actualizarlo y para modificarlo». Sexto: el concierto vasco se caracteriza, finalmente, «por el hecho de que los tributos concertados, en puridad teórica, no son tributos estatales cedidos, sino tributos de la Comunidad Autónoma». Vid. Viver i Pi-SunYer, C. y Martín Alonso, G.: «Informe sobre l'aplicació a Catalunya d'un nou model de finançament basat en el 
fesores Carles Viver i Pi-Sunyer y Gerard Martín Alonso emitieron -el 4 de octubre de 2011 - un sólido «Informe sobre la aplicación a Cataluña de un nuevo modelo de financiación basado en el concierto económico» ${ }^{31}$. Según estos prestigiosos juristas, el modelo de concierto vasco sería aplicable a Cataluña en la actualidad, con simples cambios legislativos, esto es, sin necesidad de reformar la Constitución ni su Estatuto de Autonomía. Las conclusiones a las que se llega en dicho Informe son, en esencia, las siguientes: «Primera: $(\ldots)$ existen buenos argumentos jurídicos para afirmar que la aplicación a Cataluña de un sistema de financiación basado en el concierto (vasco) no entraría en contradicción con ninguno de los preceptos constitucionales que le serían aplicables. La aplicación a Cataluña de este nuevo modelo de financiación podría justificarse de acuerdo con las exigencias constitucionales. Segunda: existen buenos argumentos jurídicos para afirmar que la aplicación a Cataluña de un sistema de financiación basado en el concierto (vasco) no vulneraría ninguno de los artículos del Estatuto de Autonomía de 2006 (...). Tercera: existen buenos argumentos jurídicos para afirmar que la aplicación a Cataluña de un sistema de financiación basado en el concierto (vasco) no contraviene el Derecho europeo, ni el originario ni el derivado, a pesar de que en su concreción y aplicación será necesario que respete los principios derivados de la libre circulación de mercancías, la libre competencia y la unión económica (...). Cuarta: el establecimiento en Cataluña de un modelo basado en el concierto (vasco) se ha de articular normativamente a través de una reforma de la LOFCA, en la cual se proclame la excepción del régimen de financiación común y, además, se regulen los rasgos más esenciales u orgánicos de este modelo (...). Quinta: la no previsión del nuevo modelo de financiación en la Constitución o en el Estatuto de Autonomía, y su establecimiento a través de la LOFCA, implica que no podrá disfrutar de una garantía jurídica absoluta ante hipotéticas decisiones unilaterales del Estado de supresión o alteración. Sin embargo, es necesario tener presente que pueden preverse mecanismos que refuercen al máximo el carácter de pacto bilateral, tanto respecto del procedimiento de incorporación de este nuevo modelo en la LOFCA, como de sus modificaciones futuras y de la aprobación de las disposiciones generales que desarrollen y concreten el modelo (...). Octava: un régimen de financiación basado en el modelo del concierto (vasco) no tendría por qué afectar, a priori, el régimen de financiación autonómico común, previsto en la Ley 22/2009, de 18 de diciembre, por la cual se regula el sistema de financiación de las Comunidades Autó-

concert econòmic», en Tres informes de l'Institut d'Estudis Autonòmics sobre el pacte fiscal, les duplicitats i les consultes populars, Institut d'Estudis Autonòmics (Generalitat de Catalunya), Barcelona, 2013, pp. 13-16 (la traducción del catalán es nuestra).

31 Viver i Pi-Sunyer, C. y Martín Alonso, G.: «Informe...», op. cit., pp. 9-121.

UNED. Teoría y Realidad Constitucional, núm. 37, 2016, pp. 221-248 
nomas de régimen común, aparte de establecer una exclusión de la Generalidad de Cataluña. Novena: se podría configurar el nuevo sistema de financiación sin que una mayor disponibilidad de recursos para la Generalidad de Cataluña supusiera una menor disponibilidad de recursos para las otras Comunidades Autónomas. Esto podría hacerse bien mediante la aportación de más recursos por parte del Estado al sistema de financiación común, o bien imputando la reducción de las aportaciones de la Generalidad de Cataluña a los cometidos generales del Estado y no a la solidaridad con otras Comunidades Autónomas. Décima: la regulación del nuevo modelo de financiación afectaría a cinco grandes ámbitos materiales normativos estatales: el tributario, el presupuestario, el relativo a la financiación local, el procesal y el constituido por aquellas disposiciones de cualquier ámbito material que requirieran financiación» para poderlas poner en planta ${ }^{32}$.

Desde el ámbito de la patronal catalana, Fomento del Trabajo, su Presidente, Joaquim Gay de Montellà, planteó —el día 12 de diciembre de 2013, en el Club Siglo XXI de Madrid- la urgente necesidad «de una financiación especial para Cataluña como solución para impedir la ruptura del Estado. "El café para todos ya no sirve", afirmó». A su juicio, es urgente trabajar en el logro del denominado "pacto fiscal, es decir, la revisión del sistema de financiación de Cataluña, por el convencimiento de que, después de treinta años de pacto constitucional y de evolución del Estado de las Autonomías, Cataluña acumula un desequilibrio fiscal difícil de asumir, que le resta competitividad general y genera malestar social». Y añadió: «En el caso de que se evidenciara claramente que la Constitución no recoge esta posibilidad, el propio proceso político debería consensuar una reforma de la misma que diera el espacio necesario a un pacto fiscal para Cataluña» ${ }^{33}$. Además, como ha puesto de relieve el catedrático de Derecho Constitucional y magistrado del Tribunal Supremo Pablo Lucas Murillo de la Cueva ${ }^{34}$, «en la insatisfacción del vigente sistema de financiación autonómica reside buena parte del descontento catalán». Con idéntico criterio pero más expresivo, el profesor Castellà Andreu $^{35}$ afirma que una de las razones del gran incremento del independentismo catalán de los último años hay que buscarlo (además de en los es-

32 Ibidem, pp. 117-110 (la traducción del catalán es nuestra).

33 Segovia, C.: «La patronal catalana: "El café para todos ya no sirve"», en El Mundo, día 12 de diciembre de 2013 , p. 31.

34 Lucas Murillo de la Cueva, P.: «La forma y la permanencia del Estado. (Observaciones sobre la organización territorial del poder político)», en el anuario Parlamento y Constitución, n. ${ }^{\circ}$ 15, 2012-2013, p. 33 .

35 Castellà Andreu, J.M.: «La secesión catalana, entre la política y el derecho», en Anuario de la Facultad de Derecho de la Universidad de Alcalá, vol. VII, 2014, p. 234. 
tragos jurídicos y políticos de la STC 31/2010, a los que nos referiremos más adelante) en «la negativa del gobierno Rajoy a negociar un "pacto fiscal"... a partir del modelo vasco y navarro de "concierto"... Se considera que el actual sistema de financiación perjudica notablemente a Cataluña — con la expresión de resonancias en la Lega Nord "Espanya ens roba" - y se alegan cálculos de balanzas fiscales en apoyo de esta tesis». Un dato muy relevante es el que pone de relieve Xavier Vidal-Folch ${ }^{36}$, al subrayar que el deseo de un Estado independiente catalán disminuye si se confronta "con la posibilidad de conseguir un "pacto fiscal" (una suerte de concierto a la vasca, pero con elementos de solidaridad interterritorial)». Reiteramos que no nos parece en absoluto que sea un dato a despreciar o menospreciar.

3. Tercera singularidad. Cataluña y el País Vasco deberían gozar de total y absoluta libertad para fijar su propia organización institucional. Un artículo como el 152.1 de la Constitución («...la organización institucional autonómica se basará en una Asamblea Legislativa, elegida por sufragio universal, con arreglo a un sistema de representación proporcional que asegure, además, la representación de las diversas zonas del territorio; un Consejo de Gobierno con funciones ejecutivas y administrativas y un Presidente, elegido por la Asamblea de entre sus miembros, y nombrado por el Rey, al que corresponde la dirección del Consejo de Gobierno, la suprema representación de la respectiva Comunidad Autónoma y la ordinaria del Estado en aquella. El Presidente y los miembros del Consejo de Gobierno serán políticamente responsables ante la Asamblea») seguiría siendo posible e incluso aconsejable para los quince Estados-miembros de la Federación Española, pero no para los dos Estados-libres-asociados. En efecto, estos — dada la libertad máxima de que deberían gozar en todos los ámbitos, siempre que no se pusiera en peligro la propia existencia de la Federacióndeberían carecer de límites en temas organizativos. Así, podrían establecer un Parlamento unicameral o bicameral, podrían fijar sin límites el sistema electoral que prefirieran, esto es, proporcional o mayoritario (tanto uno como otro en cualquiera de sus múltiples variantes), teniendo en cuenta o despreciando el elemento territorial, a una vuelta o a dos vueltas, con barrera electoral o sin ella (y, si hubiera barrera, con libertad en la fijación de su umbral), con capacidad para fijar la mayoría de edad electoral, el censo, las circunscripciones, los recursos, etc. Asimismo, podrían optar por un Presidente bicéfalo (de la Comunidad y del Gobierno) o separarse en dos personas distintas ambos cargos. Cabría un modelo parlamentario de elección del Presidente (con moción de censura y disolución anticipada del 
Parlamento por parte del Presidente del Gobierno) o un modelo presidencial de elección ciudadana directa (tipo norteamericano o francés), con rígida separación entre el Ejecutivo y el Legislativo. En cuanto al Poder Judicial, podrían crear una estructura judicial propia e independiente de la del resto de la Federación y su Tribunal Superior sería, si así lo desearan, la última instancia judicial ordinaria, sin perjuicio del recurso de amparo ante el Tribunal Constitucional y del recurso ante el Tribunal Europeo de Derechos Humanos, en ambos casos exclusivamente para la tutela de ciertos derechos fundamentales (los consagrados en los artículos 14 a 29 y 30.2 de la CE, en el primer caso, y los reconocidos en el Convenio Europeo para la protección de los derechos humanos y de las libertades fundamentales, en el segundo). Asimismo, serían de libre creación, organización y fijación de sus competencias todos los órganos de autogobierno de segundo nivel que Cataluña o el País Vasco estimasen necesarios o convenientes (tribunales de garantías estatutarias, consejos consultivos, consejos económicos y sociales, consejos de justicia, defensores del pueblo, tribunales de cuentas, consejos audiovisuales, órganos de proyección y representación internacional, etc.). La Federación Española en este ámbito no tendría, ni por activa ni por pasiva, nada que decir.

4. Cuarta singularidad. En cada uno de los dos Estados-libres-asociados, su lengua propia (catalán o vasco) tendría carácter de lengua oficial y todos sus ciudadanos tendrían el deber de conocerla y el derecho a usarla (exactamente en los mismos términos que el español, que sería la lengua común de la Federación). No debemos olvidar que, según reiteradas encuestas del Centro de Investigaciones Sociológicas ${ }^{37}$, la existencia de una lengua propia es el factor principal que invocan los ciudadanos para considerar a su Comunidad Autónoma como una «nación». En sentido totalmente contrario al que nosotros proponemos se manifestó, el 10 de octubre de 2012, el entonces Ministro de Educación, Cultura y Deportes - José Ignacio Wert Ortega- cuando, al responder a una pregunta oral del diputado socialista catalán Francesc Vallès, afirmó que el propósito del Gobierno era «españolizar a los alumnos catalanes», lo que, según él, se iba a producir a través del Proyecto de ley que presentaba ${ }^{38}$. Es difícil hacer más daño a la unidad del Estado español con menos palabras. El profesor Joan Marcet, en un trabajo muy recomendable ${ }^{39}$, afirma que «la práctica de gobierno

37 Estudios del CIS número 2.228 realizado en 1996 (referido a todo el Estado) y números 2.402, 2.410 y 2.413 realizados en 2001 (referidos, respectivamente, al País Vasco, Cataluña y la Comunidad Valenciana).

38 Se refería, como es obvio, a la L.O. para la mejora de la calidad educativa (LOMCE), duramente contestada por la práctica totalidad de los sectores educativos y políticos (excepto el Partido Popular, claro está)

39 Marcert i Morera, J.: «La política lingüística de l'Estat espanyol: una aproximació a la incomprensió del pluralisme cultural», en Revista de Llengua i Dret, n. ${ }^{\circ}$ 59, 2013, p. 61 (la traducción del catalán y las cursivas son nuestras). 
del Partido Popular en las Comunidades Autónomas que ha dirigido ha tendido, en los últimos tiempos, a deshacer una parte del camino recorrido. En Galicia, Islas Baleares, Comunidad Valenciana y Aragón se han producido, en los últimos meses, iniciativas en el sentido de deshacer buena parte del camino recorrido por los propios gobiernos del PP durante los años ochenta, noventa y primera década del 2000. Se vuelve a poner en valor la existencia de una lengua española común, el castellano, y se tiende a poner en segundo plano las lenguas propias de las Comunidades Autónomas», bien sea impulsando un modelo escolar trilingüe (reduciendo, por tanto, las horas de enseñanza en la lengua propia), bien sea rebajando la importancia de las lenguas cooficiales (por ejemplo, convirtiendo su conocimiento en un mérito, en vez de un requisito, para el acceso a la Administración autonómica).

Nuestra propuesta para intentar superar la encrucijada en la que se encuentra el Estado español va, en este punto, en el sentido de dar la máxima protección y el mayor reconocimiento normativo al catalán, gallego y vasco en las Comunidades Autónomas en las que tienen rango de lenguas oficiales. En este sentido, no podemos menos que valorar en términos positivos el camino que dibujaba la Resolución en defensa del pluralismo lingüístico en España aprobada en el 37. ${ }^{\circ}$ Congreso Federal del PSOE, celebrado en julio de 2008, en donde se hallan afirmaciones del siguiente tenor ${ }^{40}$ : «Estas otras lenguas, también españolas y por lo tanto patrimonio de todos, necesitan en paralelo una proyección y una protección. No tiene sentido pensar que el castellano debe defenderse de ellas». Y en otro párrafo: «Los socialistas no pensamos que las lenguas cooficiales españolas sean una mera anécdota, algo encomiable con lo que tengamos que convivir pacientemente, sino que su estímulo y su cuidado pasa por una de nuestras prioridades, porque así lo pensamos y sentimos políticamente y porque así lo establece la Constitución, con la certeza de que ello no va en absoluto en detrimento de la lengua de todos, el castellano».

5. Quinta singularidad. Se reconocería a los dos Estados-libres-asociados el derecho a la autodeterminación, esto es, a decidir libremente su futuro colectivo dentro o fuera de la Federación Española. Somos muy conscientes del extraordinario alcance político del reconocimiento de este poder a Cataluña y a Euskadi. Precisamente por ello, dada la trascendencia de esta decisión para los ciudadanos de todo el Estado y para la propia Federación Española, el proceso de separación debería cumplir unos requisitos procedimentales muy rigurosos. En concreto, la iniciativa debería ser aprobada por, al menos, dos tercios de los integrantes de su Parlamento respectivo; y, posteriormente, 
debería ser ratificada mediante referéndum por el voto afirmativo de la mayoría absoluta de los electores (es decir, de los censados, no solo de los votantes) de cada una de las provincias ${ }^{41}$. Dadas las importantísimas consecuencias, tanto internas como internacionales, que la simple celebración de dicha consulta traería consigo ${ }^{42}$, la iniciativa de ruptura con la Federación Española solo podría plantearse transcurridos, al menos, veinticinco años de la anterior (es decir, más o menos, una generación).

La propuesta que acabamos de formular en relación a Cataluña y al País Vasco (que, obvio es decirlo, requeriría una reforma constitucional ${ }^{43}$ ) solo pretende poner de relieve la necesidad — $-\mathrm{y}$, a nuestro juicio, todavía la posibilidad- de buscar un encaje específico y singular de Cataluña y el País Vasco dentro del Estado espa$\tilde{n} o l$. Esta es, a pesar de las poderosas fuerzas que se oponen, la senda que hay que recorrer. Lo cual, al menos como punto de partida, tampoco sería tan original. Ciertamente, en otros momentos de nuestra historia reciente se han buscado fórmulas de convivencia en el Estado español que subrayaban la singularidad de aquellas dos naciones. En efecto, como afirma con lucidez el profesor Ruiz Roble$\mathrm{do}^{44}$, «la vía que habría que explorar sería la de buscar un encaje constitucional específico para Cataluña. Algo de eso — sigue diciendo el catedrático de la Universidad de Granada - había ya en el texto original de la Constitución de 1978 cuando ofrecía dos soluciones para dos problemas: una autonomía muy amplia para integrar a las nacionalidades y una más reducida para organizar a las regiones. Esta lógica de la dualidad fue luego mutada en los Acuerdos Autonómicos de 1981 en una lógica de la homogeneidad. Pasqual Maragall intentó en la década

41 Un requisito análogo es el que exigía el artículo 151.1 de la Constitución Española de 1978 para que una proyectada Comunidad Autónoma pudiera acceder a la autonomía plena por la vía rápida sin reunir los requisitos que exigía la disposición transitoria segunda de la CE. Vid. Oliver Araujo, J.: «El referéndum en el sistema constitucional español», en Revista de Derecho Político, n. ${ }^{\circ}$ 29, 1989, esp. pp. 164-166.

42 El profesor G. Ariño Ortiz (La independencia de Cataluña. Historia, Economía, Política y Derecho, Thomson Reuters Aranzadi, Cizur Menor - Navarra-, 2015, pp. 206 y 215), sobre los costes de la consulta, ha escrito: «... la mera consulta con la amenaza de separación, cualquiera que sea la forma en que se produzca, llevaría... costes no pequeños. Hasta ahora, el mundo empresarial, las empresas de rating y los bancos y fondos internacionales, aunque se han pronunciado en contra de cualquier secesión, no la han descontado en sus cálculos, porque no creen que esta se vaya a materializar. Pero si esto se aproximase como posibilidad real, tenemos la experiencia de lo sucedido en otros lugares con fenómenos como este. Un caso bien estudiado es el de Quebec. Después de las amenazas de separación protagonizadas por el partido quebequés en 1976, 1980 y 1990-95, el crecimiento de la economía de Quebec ha experimentado un descenso de más de 30 puntos en relación con el resto del Canadá (76'6\% frente a 109'9\%), con huida de la población a Ontario y otras provincias del país. En Cataluña podría pasar lo mismo». Además, «en todo caso, la sociedad queda partida en dos y la vida y la convivencia se hace más difícil de lo que era antes de referéndum».

43 Sobre la reforma constitucional y sus dificultades, se han escrito recientemente tres obras de gran interés. En concreto, Pérez Royo, J.: La reforma constitucional inviable, Los Libros de la Catarata, Madrid, 2015; Tornos Mas, J.: De Escocia a Cataluña. Referéndum y reforma constitucional, Iustel, Madrid, 2015; MARTínez CAlvo, J.: Los límites de la nación y la reforma constitucional en España, Tirant lo Blanch, Valencia, 2015.

44 Ruiz Robledo, A.: «Lifting constitucional», en El País (edición de Andalucía), día 17 de enero de 2014 , p. 4 (las cursivas son nuestras). 
del 2000 lo que el mismo consideró una vuelta a los orígenes». De forma reiterada, aunque a veces con sordina, el Partit dels Socialistes de Catalunya viene proponiendo introducir en la Carta Magna una nueva disposición adicional que señale esa posición singular de Cataluña. Sin embargo, lamentablemente, aunque algunos dirigentes socialistas estatales han considerado que era una propuesta digna de ser estudiada a la hora del encontrar el encaje de Cataluña en el Estado español, la mayoría de ellos —al menos los que han hecho más ruido en los medios de comunicación - «han rechazado esa propuesta con unas prisas que más parecen responder a una estrategia interna y electoral que a considerarla una salida equivocada al laberinto catalán».

\section{YA NO SE PUEDE NI «CONLLEVAR»... LA HORA DE LA POLÍTICA EN MAYÚSCULAS}

José Ortega y Gasset afirmaba, durante la Segunda República española ${ }^{45}$, que el problema catalán no se podía resolver, solo se podía «conllevar» ${ }^{46}$. Literalmente afirmó lo siguiente: «Yo sostengo que el problema catalán, como todos los parejos a él, que ban existido y existen en otras naciones, es un problema que no se puede resolver, que solo se puede conllevar, y al decir esto, conste que significo con ello, no solo que los demás españoles tenemos que conllevarnos con los catalanes, sino que los catalanes también tienen que conllevarse con los demás españoles». Pues bien, según el Diccionario de la lengua española ${ }^{47}$, «conllevar» significa, en su primera acepción, «sufrir, soportar las impertinencias o el genio de alguien» y, en la segunda, «sufrir otra cosa adversa y penosa». Por su parte, en el utilísimo Diccionario de uso del español, de la académica María Moliner, la segunda acepción del término «conllevar» es «vivir procurando atenuar los efectos de una enfermedad u otro motivo de mal estar». Por tanto, para Ortega el problema catalán era como una diabetes tipo 1, un sida en países desarrollados o un cáncer testicular, que te hace la vida desagradable, en algún momento muy desagradable hasta el punto de que te puede poner al borde de la muerte, pero normalmente no es mortal de necesidad. Sin embargo, a nuestro juicio, en la actualidad el problema catalán ya no se puede ni conllevar. O se resuelve definitivamente (más bien que mal) o el resultado, sea el que sea, será muy grave y de dimensiones imprevistas e imprevisibles, tal vez trágicas para Cataluña y también para el resto del Estado.

Para entender cómo hemos llegado a este punto, a esta verdadera encrucijada histórica, deberemos recordar dos hechos relativamente recientes que cercenaron,

45 Diario de Sesiones de las Cortes de día 13 de mayo de 1932.

46 El profesor F. De Carreras Serra («Prólogo» al libro de G. Ariño Ortiz La independencia de Cataluña. Historia, Economía, Política y Derecho, Thomson Reuters Aranzadi, Cizur Menor —Navarra-, 2015, p. 13) también se refiere a la «conllevancia» orteguiana.

47 Real Academia Española: Diccionario de la lengua española, 23. a edición, octubre de 2014. 
de forma muy lacerante, un deseo mayoritario de catalanes y vascos de ampliar de manera sensible su grado de autogobierno, dentro del Estado español. Como es obvio, nos referimos, por una parte, al rechazo que el Congreso de los Diputados hizo, en 2005, de la reforma del Estatuto de Autonomía del País Vasco aprobada por su Parlamento (la denominada «Propuesta del Parlamento Vasco para la convivencia en Euskadi», «Nuevo Estatuto Político de Euskadi» o, popularmente, «Plan Ibarretxe»). Y, por otra parte, nos referimos a la Sentencia del Tribunal Constitucional 31/2010, de 28 de junio, que —al objeto de desactivar, de raíz, las pretensiones catalanas ${ }^{48}$ - declaró inconstitucionales o interpretó «conforme a la Constitución» aspectos fundamentales del nuevo Estatuto de Autonomía de Cataluña de $2006^{49}$, ampliamente aprobado por el Parlamento de Cataluña, por las Cortes Generales y por el pueblo catalán a través del preceptivo referéndum ${ }^{50}$.

Dicha Sentencia traspasó, sin tener en cuenta las dramáticas consecuencias que ello iba a provocar, una delicadísima línea roja en el equilibrio de poderes entre el Estado central y Cataluña, pues supuso «una desautorización casi global del Estatuto, pero no hecha solamente como consecuencia de las declaraciones de inconstitucionalidad llevadas al fallo, sino mediante las interpretaciones contenidas en las decenas de considerandos en las que el Tribunal nos explica lo que el Estatuto en realidad debe querer decir para ser conforme a la Constitución, aunque en su texto leamos literalmente» una cosa diferente ${ }^{51}$. Se trata de un punto final. La Constitución, a juicio de la mayoría del Tribunal Constitucional, no permite ir más allá en el proceso descentralizador. Precisamente por ello - como afirma Xavier Vidal-Folch-, «la principal causa del aumento del desencanto, de la desafección hacia España como proyecto político y, en

48 Carrillo, M.: «Después de la sentencia, un Estatuto desactivado», en Derecho y Debate, n. ${ }^{\circ} 10$, 2015 (revista electrónica: www.derechoydebate.com).

49 En la misma línea de pensamiento se expresa A. Puigverd i Romaguera ( «Alea iacta est», en La Vanguardia, día 13 de diciembre de 2013, p. 16), al afirmar que «no es (Artur) Mas, ni siquiera (Oriol) Junqueras, quien está llevando a Cataluña a un callejón sin salida, fue el Tribunal Constitucional con la Sentencia sobre el Estatut del 2010. A la mayoría de los catalanes que pedían otro estatus para Catalunya dentro de España, el Alto Tribunal les vino a decir: «Alejad toda esperanza, someteos a la interpretación restrictiva de la Constitución». Tan restrictiva era aquella Sentencia que dejaba fuera de juego incluso a uno de los ponentes de la Carta Magna: Miquel Roca, seguramente el líder de la España democrática que más trabajó por la estabilidad, el equilibrio de las dos Españas y la unión en la diversidad. La Sentencia del Constitucional no fue un episodio pasajero, como la política y el periodismo de la capital esperaban. Del 2010 al 2012 se produce un cambio de paradigma en el sistema nervioso de la sociedad catalana. Los moderados — sigue diciendo A. PUIGVERD—, confundidos y sin asideros, quedamos descolocados y perdimos, no sabemos si provisionalmente, la hegemonía ideológica. El impacto de la Sentencia del TC concedió la iniciativa a los partidarios de la separación. Las manifestaciones del 2012 y del 2013 son expresión popular de este cambio de paradigma».

50 El nuevo Estatuto de Autonomía, en su redacción originaria, fue impulsado por dos socialistas (el Presidente de la Generalitat, P. Maragall, y el Presidente del Gobierno de España, J.L. Rodríguez Zapatero), que creían — sin duda de buena fe y, tal vez, con razón — que con este texto se conseguiría la integración adecuada y el encaje satisfactorio de Cataluña en el Estado español. Tenían la confianza de que con el Estatuto que habían pactado, de alguna manera, se pondría el punto final, al menos por varias generaciones, a la denominada «cuestión catalana».

51 García Ruiz, J.L.: «Trayectoria...», op. cit., pp. 54-55. 
suma, de la corriente independentista radica en la Sentencia del Tribunal Constitucional que en junio de 2010 impuso modificaciones relevantes al nuevo Estatuto de Autonomía catalán. La resolución fue recibida (por el pueblo de Cataluñat como un recorte competencial, una dilución del alcance de las pretensiones nacionales y una reinterpretación bajista sobre la posibilidad de acción autónoma de Cataluña». Y sigue afirmando Vidal-Folch: «Pero tan o más importante que esas contrariedades jurídicas fue el estrago en la percepción política del asunto, pues el Tribunal modificó un texto que había sido pactado (por el Parlament) con las Cortes y votado en referéndum por los ciudadanos de Cataluña, lo que muchos digirieron como una victoria de la legalidad institucional sobre la legitimidad democrática, de facto contrapuestas en este caso. Además, la tardanza en resolver, los huecos producidos por muertes y recusaciones en la composición del Tribunal Constitucional» y el hecho de que varios de sus magistrados ya hubieran agotado ampliamente su mandato sin haber sido sustituidos (todo ello a causa de intencionada parálisis parlamentaria), «contribuyeron a su desprestigio. Asimismo, bastantes artículos retocados por el Tribunal siguieron vigentes para otras Comunidades Autónomas (Andalucía, Comunidad Valenciana...), que se habían inspirado en el texto catalán y los habían incorporado a sus nuevos Estatutos. Pero como el Tribunal Constitucional solo podía entender del Estatuto impugnado, y el Partido Popular solo había impugnado el Estatuto catalán, resultó la paradoja —y el agravio comparativode que» lo que se prohibía a Cataluña se autorizaba a otras Comunidades ${ }^{52}$.

Ciertamente, «no hay duda de que el pistoletazo de salida del soberanismo hacia la independencia, arrastrando en la aventura a mucha gente moderada que no estaba originariamente por la secesión, ha de buscarse precisamente en aquella descabellada sentencia, que perturbaba la lógica interna de nuestra Constitución al ser posterior a un referéndum», votado afirmativamente por la inmensa mayoría de la ciudadanía catalana ${ }^{53}$. El ex Presidente Artur Mas, al responder a la pregunta sobre cuándo había dado el paso del nacionalismo pactista al independentismo, contestó: «Desde el día en que el Tribunal Constitucional dictó la sentencia sobre el Estatuto». A raíz de la presentación de su libro La reforma constitucional inviable $e^{54}$, el profesor Javier Pérez Royo declaró a la prensa catalana que, «desde la sentencia del Tribunal Constitucional que echó abajo la reforma del Estatut catalán nacida del acuerdo político, España carece de Constitución territorial. La Carta Magna de 1978 estableció la integración de las nacionalidades en el Estado como un acto complejo que negociaban el Parlamento del Estado y el de la nacionalidad correspondiente. Y establecía sistemas de garantía: el Estado debía aprobar en las Cortes el texto autonómico, y la autonomía consultaba

52 Vidal-Folch de Balanzó, X: ¿Cataluña..., op. cit., pp. 137-138.

53 Papell Cervera, A.: «Cataluña y la voladura constitucional», en Diario de Mallorca, día 11 de octubre de 2015, p. 32

54 Vid. supra nota 43

UNED. Teoría y Realidad Constitucional, núm. 37, 2016, pp. 221-248 
a su pueblo en referéndum si aceptaba o no las posibles modificaciones establecidas por el Estado. Eso se rompe en el 2010» ${ }^{55}$.

Con ambas decisiones, especialmente con la segunda, el Estado español decidió que no cabía incrementar la autonomía competencial de las Comunidades sin una reforma de la Constitución. En consecuencia, la posibilidad de aumentar el poder territorial por la vía de la interpretación de la Carta Magna de 1978 se declaraba, de facto y de iure, cerrada. El Tribunal Constitucional, con argumentos muy discutibles y discutidos, considera que la Constitución no da más de sí. Precisamente por ello, los nacionalistas catalanes y vascos han dejado de considerarla un campo de juego adecuado y están planteando sus reivindicaciones fuera (que no, necesariamente, en contra) del marco constitucional. No podemos, por tanto, ignorar que «hay un conflicto larvado y cada vez más intenso entre la legalidad y la legitimidad, que en un terreno como este tiene un potencial conflictivo» de gran magnitud ${ }^{56}$. Con el mismo criterio, Antoni Bassas ha afirmado que «desde Cataluña se apela a la democracia y desde España, a la ley. Pero incluso en el supuesto de que se impidiera la celebración de la consulta $(. .$.$) el pleito está aquí para quedarse, y con una fuerte legitimidad$ política y social. No es posible ventilar la cuestión con una prohibición. O con el miedo. Ni ante los catalanes ni ante el mundo, porque el litigo», sin duda, va a continuar ${ }^{57}$.

Este grave conflicto entre Cataluña y el resto del Estado es, sin duda, un conflicto de naturaleza política. Así lo han reconocido dos de los padres de la Constitución de 1978 —Miguel Herrero y Rodríguez de Miñón y Miquel Roca Junyent-, al afirmar que se trata de un problema político que solo puede resolverse en dicho ámbito, para buscar seguidamente su encaje jurídico-constitucional. Si se niega esta realidad, queriendo buscar soluciones solo normativas, ancladas en principios que se entienden inmutables (casi como las tablas de la ley del Sinaí), en vez de considerar los preceptos constitucionales como meros acuerdos históricos, fruto de la correlación de fuerzas existente en un cierto momento político (Lassalle) y, por lo tanto, susceptibles de revisión y cambio, estaremos condenando el problema catalán (y también el vasco) al pudridero y, más pronto o más tarde, al estallido social. Si llegamos a este punto, los resultados, sean los que sean, serán — como ya hemos apuntado - muy graves para todas las partes implicadas. De este enorme problema, tan evidente para numerosos juristas y políticos sensatos, no parece, sin embargo, darse cuenta el Gobierno del Sr. Rajoy, que está «cerrado en banda, con sus argumentos jurídicos siempre a mano como única respuesta ${ }^{58}$. El Gobierno español, con una visión del problema catalán

55 La Vanguardia, día 9 de octubre de 2015.

56 Grupo de Reflexión del PSOE-A: Por una reforma..., op. cit., apartado 1, p. 23.

57 Bassas i Onieva, A. «Guanya l'argument i guanyaràs el vot», en Ara, día 13 de diciembre de 2013, p. 3 (la traducción del catalán es nuestra).

58 Ariño Ortiz, G.: La independencia..., op. cit., p. 182. 
muy cortoplacista, «se ha escudado en la Constitución para justificar su posición, evitando un planteamiento político de la cuestión, y para cerrarse a todo diálogo» ${ }^{59}$. Los autores que hacen esta crítica al Ejecutivo español no son, precisamente, independentistas irredentos.

El profesor Luis López Guerra ${ }^{60}$, Catedrático de Derecho Constitucional y Magistrado del Tribunal Europeo de Derechos Humanos, en términos genéricos aunque perfectamente concretables, nos ha recordado la especial simbiosis que, a veces, debe darse entre el acuerdo político y su plasmación constitucional. Su razonamiento es del siguiente tenor: «...en ocasiones, la construcción de un marco constitucional de convivencia ha resultado de acuerdos, pactos y compromisos políticos, que han sido luego traducidos al Derecho. En esas ocasiones, tras la veste formal de la Constitución como voluntad del llamado poder constituyente, lo que se encontraría sería un pacto como resultado de voluntades colectivas puestas de acuerdo». Ni el actual Gobierno ni los que le seguirán en el futuro deberían olvidar este provechoso modus operandi, que de tantos atolladeros nos sacó durante el último proceso constituyente y en la etapa inmediatamente posterior.

\section{LA CONVENIENCIA (Y, POSIBLEMENTE, LA NECESIDAD) DE QUE EL PUEBLO DE CATALUÑA (Y, TAMBIÉN, EL DEL PAÍS VASCO) APRUEBE EL NUEVO ENCAJE JURÍDICO DE SU NACIÓN DENTRO DEL ESTADO ESPAÑOL}

La expresión «derecho a decidir» ${ }^{61}$, jurídicamente tan imprecisa y ambigua, ha calado hondamente en la ciudadanía catalana, al identificarla con la esencia del principio democrático ${ }^{62}$. Todas las encuestas subrayan que una amplia mayoría de catalanes (incluso muchos de los que se darían por satisfechos con un Estado federal, como numerosos socialistas, militantes de Unió Democràtica de Catalunya y votantes de Iniciativa per Catalunya Verds) reclaman $s u$ derecho a decidir si Cataluña debe continuar dentro del Estado español o debe independizarse para seguir su propio camino. En efecto, existe «una abrumadora mayoría transversal partidaria de la celebración de un referéndum sobre el futuro encaje político de

59 Castellà Andreu, J.M.: «La secesión...», op. cit., p. 235.

60 López Guerra, L.: «Prólogo» a la obra colectiva El futuro territorial del Estado español Centralización, autonomía, federalismo, confederación o secesión? (director: JoAn Oliver Araujo), Tirant lo Blanch, Valencia, 2014, esp. p. 25.

61 Sobre el derecho a decidir, vid. Barceló i Serramalera, M.; Corretja, M.; González Bondia, A.; López, J.; y Vilajosana, J.M.: El derecho a decidir. Teoría y práctica de un nuevo derecho, Atelier, Barcelona, 2015; SAgarra Trías, E. (coord.): ¿Existe el derecho a decidir? Preguntas y respuestas sobre el proceso abierto en Cataluña, Tibidabo, Barcelona, 2014; Pons Rafols, X.: Cataluña. Derecho a decidir y Derecho Internacional, Reus, Madrid, 2015.

62 Castellà Andreu, J.M.: «La secesión...», op. cit., p. 237. 
Cataluña con España, que sobre todo las corrientes soberanistas subsumen bajo el lema del "derecho a decidir". Unos porque se trata de un paso democráticamente inexcusable para su objetivo de independencia; otros por el deseo de zanjar el debate con una victoria incontestable de la opción de mantener estrechos vínculos con el conjunto de España; y otros por estricto respeto al principio democrático» ${ }^{63}$.

A tenor de lo anterior y a la vista de la actual situación, creemos que es imprescindible — guste más o guste menos - que los ciudadanos catalanes voten en referéndum sobre su futuro político. Sin embargo, dicha votación no tiene por qué ser una consulta de separación o no de España (como fue la escocesa de $2014)^{64}$, pudiendo ser un referéndum para aprobar un nueva carta de autonomía (en vez de «Estatuto» ahora hablaríamos de «Constitución estatal») de acuerdo con la Constitución de 1978 reformada (en sentido federal asimétrico) en consonancia con los parámetros antes enunciados ${ }^{65}$.

No nos olvidamos, sin embargo, que muchos políticos, periodistas y medios de comunicación madrileños tienen verdadera alergia (y, al parecer, también temor) a que los catalanes puedan expresar libre y cuantitativamente sus preferencias sobre su modelo territorial ${ }^{66}$. Así, en relación con la consulta absolutamente descafeinada e inofensiva del 9 de noviembre de 2014, una desafiante Victoria Prego ${ }^{67}$ recordaba que «el Estado todavía no se ha hecho definitivamente presente en este conflicto, pero son muchos sus poderes e infinita su fuerza, no se olvide». Y, en la misma línea, la entonces líder de Unión Progreso y Democracia, Rosa Díez, pidió la máxima firmeza al Presidente del Gobierno, de modo que, si Cataluña da un paso más en esta dirección (esto es, en el proceso de autodeterminación), se aplique el artículo 155 CE y se suspenda la autonomía en este territorio $^{68}$. Sin embargo, ante tanta llamada al Gobierno del Estado para que no le

63 Vidal-Folch de Balanzó, X.: ¿Cataluña..., op. cit., pp. 136-137.

64 Breda, V.: «La devolution de Escocia y el referéndum de 2014: ¡cuáles son las repercusiones potenciales en España?», en Teoría y Realidad Constitucional, n. ${ }^{\circ} 31,2013$, pp. 69-88.

65 Vid. supra: «3.2. Una solución razonable (el "federalismo asimétrico" o "federalismo dual"): el reconocimiento constitucional de un estatus jurídico específico a Cataluña y al País Vasco a modo de Estados-libres-asociados, que les otorgue el máximo autogobierno compatible con el Estado español».

66 La misma alergia o temor, dicho sea de paso, que tiene la Corona española a saber por vía de referéndum el apoyo que realmente le brindan los ciudadanos.

67 Prego de Oliver y Tolivar, V.: «Encerrados», en El Mundo, día 13 de diciembre de 2013, p. 26.

68 Cercano a este planteamiento se halla el profesor J. Ruipérez Alamillo ( La nueva reivindicación de la secesión de Cataluña en el contexto normativo de la Constitución Española de 1978 y el Tratado de Lisboa», en Teoría y Realidad Constitucional, n. ${ }^{\circ} 31,2013$, pp. 125-126), al afirmar lo siguiente: «... cualquier intento del nacionalismo de ámbito regional de poner en marcha un proceso independentista, y lo mismo da que la culminación de este sea la de la ruptura total con el Estado español o la de establecer una relación de libre asociación, solo puede entenderse como una clara, manifiesta, patente e inequívoca infracción del vigente Texto Constitucional. Estaríamos, en efecto, ante el mayor y más grave de los supuestos de los incumplimientos de las obligaciones constitucionales y legales por parte de los poderes constituidos del nivel regional. Y no puede olvidarse, a este respecto, que fue el propio Constituyente originario [...] el que se preocupó de prever una respuesta jurídica y política para una tal infracción. A ello responde el artículo 155. Su finalidad última es la de lograr 
tiemble el pulso para poner orden en Cataluña y meter en vereda a los independentistas, no nos resistimos a recordar la sabia advertencia de Napoleón Bonaparte sobre las bayonetas: sirven para todo, menos para sentarse sobre ellas.

Sin embargo, es justo reconocer y poner en valor que, también en la capital del Estado, abundan políticos y académicos que se esfuerzan por ver el problema catalán sin miopías intencionadas y por buscar soluciones o «terceras vías» ${ }^{69}$. Un ejemplo paradigmático sería el profesor Ariño Ortiz ${ }^{70}$, Catedrático de Derecho Administrativo en la Universidad Autónoma de Madrid, quien — casi como súplica - afirma: «Ni independencia ni seguir como estamos... Su inmovilismo (el del Presidente del Gobierno central, Mariano Rajoy), su mensaje monocorde, sin más argumento que la legalidad (algo que en un proceso de independencia le trae sin cuidado a los protagonistas), la pobreza de argumentos históricos, económicos y sociales, que apenas se han dado, y ninguna propuesta en positivo desde el Gobierno de Madrid han condenado a este y a su partido en Cataluña a su práctica desaparición ${ }^{71}$ (como les ocurre a los Tories en Escocia, que solo sacan un diputado). El Sr. Rajoy — sigue diciendo el profesor Ariño- debe salir de su quietud y ofrecer una salida al Sr. Mas y a Cataluña, que les permita a ambos rectificar el camino emprendido de acciones unilaterales y hechos consumados. Eso requiere el ofrecimiento de un nuevo marco constitucional y estatutario, un nuevo régimen fiscal y un nuevo modelo de gobierno desde el poder central. Cataluña, por su parte, tiene que abandonar el referéndum de independencia (no otros posibles referéndums) y cualquier proyecto de elecciones» con voluntad plebiscitaria. De hecho, como se ha afirmado desde Cataluña ${ }^{72}$, «los partidarios de la independencia disminuyen cuando se ofrecen soluciones distintas del status quo (lo que se conoce como «terceras vías»)».

Frente al impecable modelo democrático del Reino Unido ${ }^{73}$, que permitió que los escoceses decidieran libremente si querían mantenerse en la Unión o

el restablecimiento del orden constitucional. Para lo cual, el Senado, habiendo apreciado que el incumplimiento por parte de la Comunidad Autónoma es doloso, autorizará al Gobierno de la Nación a adoptar cuantas medidas coercitivas sean necesarias para obligar a las autoridades regionales a cumplir la Constitución. La medida más extrema, y, por ello mismo, la menos deseable, sería la utilización de la fuerza armada. Pero caben otras muchas. Entre ellas, la de la suspensión» del Estatuto de Autonomía de la Comunidad Autónoma infractora. Lo que - a juicio del catedrático de la Universidad de Coruña — no puede entenderse «como una agresión caprichosa y arbitraria de la organización política central al autogobierno catalán».

$69 \mathrm{El}$ profesor G. Ariño OrTiz (La independencia..., op. cit., p. 182), tras subrayar que «el cuadro actual no puede ser más desolador», afirma que, entre las posiciones más radicales, «ha surgido también un conjunto variopinto de «terceras vías» sin que ninguna tenga la posibilidad de ser escuchada (al menos por el momento)».

70 Ariño Ortiz, G.: La independencia..., op. cit., pp. 217-218 (la cursiva es nuestra).

71 En las últimas elecciones al Parlamento de Cataluña (las plebiscitarias del 27 de septiembre de 2015), el Partido Popular obtuvo 11 diputados (de una Cámara de 135), perdiendo ocho escaños y más de 130.000 votos respecto a las elecciones de 2012, con el agravante de que la tasa de participación ciudadana fue diez puntos superior (la más alta de todas las elecciones autonómicas celebradas en el Principado).

72 Castellà Andreu, J.M.: «La secesión...», op. cit., pp. 233-34.

73 Haciendo la comparación entre el ordenamiento constitucional británico y el español en este punto, el profesor Agustín Ruiz Robledo («Lifting...», op. cit., p. 5) ha escrito: «... si el Gobierno central (español) 
seguir el camino de la República de Irlanda hacia la independencia, el Estado español se ha negado radicalmente siquiera a hablar del tema. Londres optó, de forma inteligente, por seducir a los escoceses (y los sedujo y optaron ampliamente por mantenerse dentro del Reino Unido $\left.{ }^{74}\right)$. Madrid, por su parte, hasta el momento, está amenazando a los catalanes con todo tipo de desgracias y males si se les ocurre expresar de forma ordenada y fiable (esto es, en un referéndum) cuál es el futuro que desean. Al demos escocés se le reconoció su mayoría de edad política $^{75}$, en tanto que al demos catalán se le niega. No es solo que no piensen atender la voluntad política que pudiera expresar el pueblo catalán, es que ni siquiera se le va a permitir que la exprese. Josep Antoni Durán i Lleida, a pesar de su moderación habitual y su posición contraria a la independencia, lamenta «el temor y alergia» a conocer la voluntad de los catalanes (es decir, a saber «lo que desearían los catalanes»). Si las cosas suceden como nos barruntamos (esto es, impidiendo que el pueblo catalán vote en un referéndum su futuro político), la tensión política se irá incrementando hasta extremos que ni siquiera queremos imaginar. Ello tendrá, como mínimo, las siguiente consecuencias (y todas ciertamente preocupantes): en primer lugar, incremento del sentimiento independentista en Cataluña (es decir, del deseo de ejercer el ius secessionis) preñado de odio contra España; en segundo lugar, animadversión — cuando no manifiesta antipatía - de los ciudadanos del resto del Estado contra los insolidarios catalanes; en tercer lugar, grave deterioro de la imagen política de España en el extranjero; y, en cuarto lugar, nefastas consecuencias financieras, bursátiles y económicas a causa de todo lo anterior (en este sentido, el Wall Street Journal subrayaba «los enormes riesgos en juego para las dos partes»). A modo de síntesis de lo anterior, podemos recoger las palabras de Antoni Puigverd ${ }^{76}$, cuando afirma que «lo que ahora nos espera no es apto para espíritus delicados: la tensión irá in crescendo. La gran polvareda que levantará el previsible choque impedirá percibir los trabajos de reparación de puentes en los que se afanarán los moderados. [...] Se acercan tremendas curvas, y el cinturón de seguridad no servirá de mucho». Además, tampoco es lógico pensar que los independentistas catalanes aceptarán sin más el portazo en la cara del Estado. Antes al contrario,

aceptara el reto independentista, como en su momento hicieron Canadá y el Reino Unido, creo que la Constitución no sería obstáculo para realizar el referéndum».

74 Aunque fuera al precio de prometerles — a última hora — una amplísima autonomía política, de compleja puesta en planta, como se está viendo.

75 En 2011, el Scottish National Party (SNP) consiguió «una gran victoria: obtuvo mayoría en el Parlamento escocés y había hecho al electorado la promesa de promover la independencia de Escocia. Camerón (Presidente del Gobierno de la Gran Bretaña) entendió que si la mayoría de escoceses querían plantearse su separación de Inglaterra y de la Gran Bretaña, él no era quien para negarles ese derecho. (...) al día siguiente de la victoria (del $S N P$ ), David Cameron aceptó que a Escocia se le debía autorizar el referéndum si el Gobierno

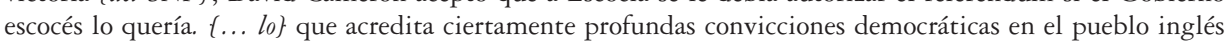
(...)». Ariño Ortiz, G.: La independencia..., op. cit., pp. 214-216.

76 Puigverd i Romaguera, A.: «Alea...", op. cit., p. 16. 
tras la negativa del Gobierno central y del Tribunal Constitucional a que se celebre en Cataluña la consulta sobre su futuro (usando, a tal efecto, todos los instrumentos políticos y jurídicos que tiene a su alcance), el Presidente de la Generalitat (con una mayoría absoluta independentista en el Parlament ${ }^{77}$ ) mantendrá, al menos formalmente y en los discurso de consumo interno, la hoja de ruta soberanista y el camino emprendido para construir un Estado independiente $^{78}$. Como ha subrayado el profesor de Ciencia Política Antón Losada, «Cataluña encontrará su camino. Puede hacerlo con nosotros, sin nosotros o a pesar de nosotros».

Con su buen sentido jurídico habitual, el profesor Javier Pérez Royo ha afirmado que «lo que sí sabemos es que en Cataluña, posiblemente también en el País Vasco, hay una mayoría parlamentaria muy cualificada que pone en cuestión el principio de unidad política del Estado y pretende dejar de ser una Comunidad Autónoma del mismo, para pasar a ser un Estado independiente. Y que pretende que se pregunte directamente a los ciudadanos de Cataluña, si esa es también su opinión. Esta es una realidad que no va a desaparecer porque la Constitución no la contemple. Si la respuesta que se le da a la manifestación de voluntad de independencia es que no existe porque la Constitución no lo permite, lo que cabe esperar es que dicha manifestación de voluntad tenga cada vez más intensidad. El Gobierno de la nación — sigue afirmando el catedrático de la Universidad de Sevilla - no puede limitarse a utilizar la Constitución como una trinchera frente a la solicitud de un referéndum. La opción exclusivamente jurídica no puede conducir nada más que a la derrota. La Constitución es norma jurídica, pero es también pacto político. Es el punto de intersección entre la política y el derecho y ambos, política y derecho, tienen que ser tomados en consideración ante un problema de naturaleza constitucional, especialmente cuando se trata de un problema existencial, como es el de la estructura» del propio Estado ${ }^{79}$. Y, en la misma línea, el profesor Joan Subirats ha señalado que «hay quienes creen que con negar la posibilidad legal de celebrar la consulta, todo está resuelto. Para mí — sigue diciendo el catedrático de la Universidad Autónoma de Barcelona-, lo más importante es entender que todo lo que estamos discutiendo desde hace meses, ahora con mayor apasionamiento, es un proceso que viene de lejos y que va a seguir abierto, por mucho que los del «no quiero, ni puedo» se entesten en ningunearlo o en exorcizarlo. De hecho, «muchos se han ido dando cuenta de que el tema no es un problema de élites extra-

77 En las elecciones autonómicas del 27 de septiembre de 2015, los dos formaciones abiertamente independentistas (Junts pel Sí — que agrupaba a Convergència Democràtica de Catalunya y a Esquerra Republicana de Catalunya, además de a diversas entidades y movimientos sociales — i la Candidatura d'Unitat Popular) obtuvieron, respectivamente, 62 y10 escaños, superando la mayoría absoluta, fijada en 68.

78 Gisbert, J.: «Junts pel Sí no afloja y sigue adelante con el proceso», en La Vanguardia, día 28 de septiembre de 2015, pp. 1 y 16-17.

79 Pérez Royo, J.: «El tiempo se agota», en El País, día 13 de diciembre de 2013, p. 19. 
viadas ni de dirigentes enfebrecidos. La voluntad de replantear el marco institucional en el que se asientan no solo las relaciones Cataluña-España, sino las bases de legitimación de un sistema político que hace aguas por todas partes, tiene un profundo enraizamiento» en el pueblo ${ }^{80}$.

TITLE: Catalonia, between autonomy and self-determination (a proposal)

ABSTRACT: The aforementioned thesis is right, since the Spanish autonomic state should become a federal state, following the German model. Nonetheless, we cannot forget the fact that Catalan and Basque nationalists consider that, far from satisfying their self-government expectations, the federal model is utterly insufficient. Whether we like or not, Catalonia and the Basque Country are different from the other fifteen autonomous communities. Unlike the rest, they are true nations, which (always) aim at a bigher degree of self-government. The inadequacy of the traditional federal model with regard to those two territories is quite evident, as well as the need to urgently find a realistic formula to ensure a stable coexistence within the Spanish state. Our proposal, which demands a constitutional reform, settles on the formula of «asymmetric federalism» or «dual federalism». This formula would imply the constitutional recognition of a specific legal status for Catalonia and the Basque Country as free associated states, granting the maximum degree of self-government compatible with the Spanish state. Thereby, the Spanish federal state would consist, for one thing, of fifteen «member states» or common federated states and, there again, two «free associated states».

RESUMEN: La tesis que acabamos de exponer y que consideramos acertada, esto es, que el Estado autonómico español debe transformarse en un Estado federal siguiendo el modelo alemán, quedaría, sin embargo, muy incompleta si no pusiéramos sobre la mesa el hecho de que los nacionalistas catalanes y vascos consideran totalmente insuficiente el modelo federal, que está lejos de dar satisfacción a sus deseos de autogobierno. Cataluña y el País Vasco, se quiera o no se quiera, guste o no guste, son Comunidades Autónomas (abora el nombre es lo de menos) distintas a las otras quince. Son verdaderas naciones que, a diferencia de aquellas, quieren un grado de autonomia (siempre) mayor. Resulta evidente, en estos momentos, la manifiesta insuficiencia del modelo federal clásico para aquellos dos territorios, por una parte, y la necesidad de buscar con urgencia una fórmula realista de convivencia estable dentro del Estado español, por otra. Nuestra propuesta -a través de una reforma constitucional - se puede concretar en la fórmula del «federalismo asimétrico» o «federalismo dual», que implicaría el reconocimiento constitucional de un estatus jurídico específico a Cataluña y al País Vasco a modo de Estados-libres-asociados, que les otorgase a ambos el máximo autogobierno compatible con el Estado español. De este modo, el Estado Federal español estaría integrado, por una parte, por quince «Estados-miembros» o Estados-federados de régimen común y, por otra, por dos «Estados-libres-asociados». lonia.

KEY WORDS: Autonomic state crisis, federalism, asymmetric federalism, free associated states, Cata-

Palabras Clave: Crisis del Estado autonómico, federalismo, federalismo asimétrico, Estados-libres-asociados, Cataluña.

FECHA DE RECEPCIÓN: 26.10.2015

FECHA DE ACEPTACIÓN: 15.01.2016

80 Subirats Humet, J. «Dos preguntas, un proceso», en El País, día 13 de diciembre de 2013, p. 19.

UNED. Teoría y Realidad Constitucional, núm. 37, 2016, pp. 221-248 